\title{
Target-Site-Specific Screening System for Antifungal Compounds
}

\author{
Consuelo Corrales-Maldonado, \\ Miguel Ángel Martínez-Téllez and Irasema Vargas-Arispuro \\ Centro de Investigación en Alimentación y Desarrollo, A.C.
}

Mexico

\section{Introduction}

The rapid emergence of fungicide resistance has brought a strong demand for crop protection agents with a new mode of action. One of the challenges for modern plant pathology research is the discovery of new modes of action that provide improved activity of fungicides against commercially important target, combined with assures environmental and public safety, is a critical step in safeguarding food security. This chapter reviews biochemical and molecular biological approaches that have revealed new insights into fungal growth and morphogenesis and offer potential target sites for the development of new fungicides. It also discusses prospects for exploiting these modern technologies for the development of fungicides.

Agriculture will always face crop losses caused by microorganisms. Since bible the first pages talk about pest, nowadays, in the XXI century must be added to pest, the losses caused by the effect of global climate change (Gustafson, 2011). Particularly, fungal plant pathogen that comprises an important group of microorganisms that causes significant economic losses in agriculture around the world. They are able to infect any tissue at any stage of plant growth (Garrido et al., 2010). Control of plant diseases typically depends upon the application of chemical fungicides, despite their potentially toxic effects on non-target organisms and the environment (Santos et al, 2008; Ferrer-Alcón, et al, 2009). Although effective, their extensive use for several decades has disrupted biological control by natural enemies and has led to new pathogen races that are resistant to fungicides (FernandezAcero et al., 2006). In spite of the incredible amount of biological information about fungal plant pathogens, there is a scarce commercial fungicide developed from a new knowledge approach. The absence of fungicides that are capable of acting in more than one site of action is a direct consequence of resistance to fungicides, which is common among currently used agrochemicals (Brent \& Hollomon, 2007). For example, chlorhexidine, quaternary ammonium compounds, organic acids, esters and alcohols that acts by interfering with the structure or permeability of the cell membrane, subsequently altering its barrier function (Russell, 2003). Pyribencarb cause an inhibition of the electron transport system in fungi, it has been suggested that pyribencarb inhibited succinate-cytocrome $C$ reductase in Botrytis cinerea and Corynespora cassicola and decylubiquinol-cytocrome $C$ reductase in $B$. cinerea in the same way as strobilurin fungicides. Benzimidazole fungicides, such as benomyl, act 
through specific binding of the $\beta$-tubulin subunit of fungal tubulin, which consequently interferes with microtubules assembly, which in turn is essential for numerous cellular processes, such as mitosis and cytoskeleton formation. Metal ions such copper and silver have been proposed to interact strongly with thiol groups in fungal enzymes and proteins. The inhibitory activity of these compounds may be caused by enzyme damage through binding to key functional groups, particularly sulphydril groups in plasma membrane and cytosol. Flucytosine (pyrimidine analog) the sites of action are nucleic acids, this agent is taken up by fungal cells via the enzyme cytosine permease. Biocides exhibit a multiplicity of antifungal mechanisms. The knowledge of their mechanism of action, combined with an understanding of quantitative structure activity relationships, provides an important platform from which novel biocides may emerge, offering enhanced activity and environmental acceptability (Fernandez- Acero et al., 2011).

Nowadays, new approaches based on graph-theoretical descriptors have emerged as powerful tools for the design of bioactive agents (Marrero -Ponce et al., 2008). The purpose of these approaches is to perform a massive screening of databases of heterogeneous series of compounds and to extract as much structural information as possible at different levels of chemical diversity. So, the use of methodologies and promising approaches may enable the discovery and identification of new candidates as potential fungicides. The new agrochemicals that can be designed will have a wide range of action against different species. Also, they will be able to act by different mechanisms of action and thus avoid the problems of cross-resistance (Speck-Planche et al, 2011).

\section{The use of genomics, proteomics and bioinformatics in fungicide design}

During decades, prior to the development of functional genomics, target discovery was relied on the "observation based" approach. That is, the target strategy involved screening of large numbers of small molecules against particular and desired phenotypes. From this approach, libraries of compounds were constructed with biologically derived or chemically synthesized agents who were used in a systematic manner. However, the result of this approach produced a low number of drugs (Ferrer-Alcon et al., 2009, Steffens et al., 1996). It can be stated that the pace of natural product research and the level of global interest in the particular area of our environment as risen dramatically in the past few years. This period is projected to continue for the future as the interface between biology and chemistry becomes even more blurred and public demand rises for the cost effective medications and biological agents from sustainable resources. The research approach should focus on how to discover novel plant derived natural products through molecular docking as new lead compounds for potential agents and to modify these compounds to find still more potent agents with focus being on the application of homology modeling (Singh \& Sharma, 2011). Significant improvements in the era of genomics and proteomics and concurrent progresses in bioinformatics techniques, have given rise to the expectation that the three dimensional structure or reliable homology modeling of target proteins can be achieve in a reasonably short time. Traditionally, the medical plants have provided lead for antifungal compound. Most of fungicides available today were discovered from the screening of synthetic or natural product libraries. Natural products, either as pure compounds or as standardized plant extracts, provide unlimited opportunities for new fungicides leads because of the unmatched availability of chemical diversity. Newer molecular structures as isolated from 
natural products may be suitably modified to obtain designer molecules for fungicide. Pharmacological testing, modifying, derivatising and research on these natural products represent a good strategy for discovering and developing new fungicides. The combinatorial chemistry has helped in the development of a series of similar but homologous structural compounds for testing (Singh \& Sharma, 2011).

At present, structure based-drug design and ligand-based drug design are two great strategies that can be applied for the discovery and/or development of new fungicides. Structure based-drug design relies on a knowledge of the three dimensional structure of the biological receptor, obtained through experimental methods such as X-ray crystallography or NMR spectroscopy. When the experimental structure of a target is not available, it may be possible to create a homology model of the biological receptor on the basis of the experimental structure of another known material (mostly a related protein). The use of various tools like automated computational procedures has provided a means of suggesting new drug candidates and optimizing time and resources. Sometimes the information about the three dimensional structure of the receptor is not available. In this sense, ligand-based drug design is focused on the knowleage of other molecules can be used to derive the minimum necessary structural characteristics that a molecule must present in order to bind to the receptor. Ligand-based drugs design can be applied in cases where the structure of the receptors is uknown but a series of compouds have been identified that exert the fungicide activity. It is necessary to have several compounds structurally similar with high activity, with no activity and with a range of intermediate activities. These other compounds that bind to the biological receptor of interest provides us information the minimum necessary structural characteristics that a molecule must present in order to bind to the receptor (Speck-Planche et al., 2011). Both strategies of drug discovery can be extended to and applied in the design of more effective agrochemicals, and specifically fungicides. Example of applying new technologies towards the rational design of fungicides to control phytopathogenic fungi of commercial crops was used by Fernández-Acero et al, (2006). They found substrates with antifungal properties against oomycetes, they screened compounds analogous to various phytoalexins and to flavanes derivatives which display antifungal activity against Phytophthora fungi.

The use of bioinformatics techniques to biological systems was demonstrated in the Structural Proteomics In Europe (SPINE) project, which was established to develop new methods and technology for high throughput structural biology. Developments covers target selection, target registration, wet and dry laboratory data management and structure annotation as they pertain to high throughput study (Albeck et al., 2006). How this program, there are now many databases which is constantly being updated with the latest data of groups to seek new targets, new fungicides and relevant information like new virulence factors of some fungi, some of these pages are: (www.broadinstitute.org/science/projects/fungal-genomeinitiative, http://cogeme.ex.ac.uk. www.phi-base.org, http://www.expasy.org/ and http://bioinformatics.charite.de/supernatural2/.

In the post-genomic era, new terms related with chemical "-omics" have appeared. The term "genetic chemical" describes the use of small molecules to selectively perturb gene function. When this concept is applied on a genome-wide scale it is named "chemogenomics". The application of chemogenomics to protein targets is named "chemoproteomics"; although a more explicit definition is TRAP (targeted related affinity profiling) defined as the use of 
biology to inform chemistry (Xu et al., 2007). The accumulation of proteomic information of fungal plant pathogens may be an incentive to the development of new and environmentally friendly fungicides. Particularly, Proteomics is another is a highthroughput technology that allows an in depth study of the sets of proteins synthesized in a specific sample at any specific moment. By protein profile comparison between samples, the proteins involved in specific biological processes may be revealed. One of the most interesting applications of the proteomics is its use in discovering new protein targets for drug design including fungicides (Fernandez-Acero et al., 2010; Ferrer-Alarcon et al.; 2009). It involves the identification and early validation of disease-associated targets.

The accumulation of information over the last decades, relating to a) fungal molecular genetic data, b) pathogenicity/virulence factors and c) proteomic approaches, has led to the appearance of several web-accessible databases which contribute to the fungal scientific community's development in this field. More than 50 genomes of pathogenic fungi are published in the Broad Institute Database for public perusal (www.broadinstitute.org/science/projects/fungal-genomeinitiative); and further data in the Phytopathogenic Fungi and Oomycete EST Database, COGEME, http://cogeme.ex.ac.uk/). In spite of the incredible amount of biological information about fungal plant pathogens, there is no commercial fungicide developed from a molecular approach.

\section{Pathogenesis}

As fungal pathogens have an enormous impact on plant production worldwide, the strategies they use to infect plants and to cause disease are a topic of great interest (Van De Wouw \& Howlett, 2011). Knowledge of the pathogenicity/virulence factors essential for fungal infections is very important because it represent the targets that researches must attack in the fight against these pathogens (Fernandez-Acero et al., 2011).

We define pathogenicity gene as those necessary for disease development but not essential for pathogen to complete its lifecycle in vitro. Pathogenicity genes are of interest not only to increase our overall knowledge of disease process, but also because any such gene could became a target for disease control.

The types of genes essential for pathogenesis depend on the infection process of a particular fungus. Some fungi degrade the cuticle and cell wall to enter the plant; others form specialized structures, such as appressoria, to penetrate the epidermis, while others enter the host through wounds or natural openings (Idnurm \& Howlett, 2001). Once the fungus has colonized plant, it may grow obtaining nutrients from its host without killing cells (as a biotroph); some fungi produce specialized infection structures (e.g. haustoria) during biotrophic stage. Other fungi species act killing host cells with the use of toxins (as necrotrophs) or act as hemibiotroph (biotroph and necrotroph at different stages if infection). Toxins often are major components of the arsenal or virulence determinants by necrotrophic fungi. They can be host specific or non host specific, and they kill or disable functions of host cells (Van De Wouw \& Howlett, 2011).

A number of fungal mechanisms and molecules have been shown to contribute to fungal pathogenicity or virulence, understood as the capacity to cause damage in a host, in absolute or relative terms. Among them, cell wall degrading proteins, inhibitory proteins, and 
enzymes involved in the synthesis of toxins are included. These virulence factors are typically involved in evolutionary arms races between plants and pathogens (Gonzalez Fernandez et al., 2010).

Knowledge of the pathogenic cycle and virulence factors of the fungus is crucial for designing effective crop protection strategies, including the development of resistant plant genotypes through classical plant breeding or genetic engineering, fungicides or the use of biological control strategies (Gonzalez-Fernandez et al., 2010). The determination of a specific factor as virulence or pathogenicity has been achieved by constructing defective mutants in the specific genes. The infection power of the analyzed mutants should at least decrease or disappear compared to the wild type, if the deflections of these genes in mutants produce a loss of vegetative lesion, it is logical to assume that the inhibition of this enzyme or set of enzymes by targeted strategies, should produce new fungicides. In this context, the use of natural products or related compounds as specific enzymes inhibitors is an archetype, as they would be species specific and the environmental impact would be reduced to a minimum (Fernandez-Acero et al., 2011).

A diversity of fungi, oomycetes secrete proteins and other molecules to different cellular compartments of their hosts to modulate plant defense circuitry and enable parasitic colonization, these molecules have been called "effectors". The usage of the term "effector" became popular in the field of plant-microbe interactions with the discovery that plant pathogenic gram-negative bacteria utilize a specialized machinery to deliver proteins inside host cells. More recently, a broader range of plant microbiologists have adopted the term effector and its associated concepts (Abramovitch et al., 2006). This term is now also routinely used in the fungal and oomycete literature and is becoming increasingly popular in nematology to describe secreted proteins that exert some effect on plant cells (Hogenhout et al., 2009).

Some effectors are avirulence proteins and have a 'gene-for gene' relationship with resistance proteins in the host. When a fungal avirulence gene is mutated, hosts with the corresponding resistance gene no longer detect the pathogen; this leads to a compatible interaction. Host-specific proteinaceous toxins that have an 'inverse' gene-for-gene relationship with the host, whereby the interaction leads to disease such genes would be classified as pathogenicity genes (Oliver \& Solomon, 2010). Small proteins encoded by fungal genes involved at various stage of infection, alter host cell structure and function facilitate infection. These proteins are often cysteine rich (hogenhout et al., 2009).

Fungi use signaling cascades to respond to changes in the environment by altering their gene expression. The interruption of these signaling genes results in the loss and/ or reduction in pathogenicity, as well as pleiotrophic effects on cellular processes, including mating, conidiation, growth rate and toxin production. Therefore, it is difficult to determine which aspect of fungal physiology is responsible for the loss of pathogenicity. The components of these signal transduction cascades may represent targets for the development of fungicides (Van De Wouw \& Howlett, 2011). Phytophtora infestans, one of the most destructive pathogen of potato in the history, have a remarkable speed of adaptation to control strategies such as genetically resistant cultivars, comparison with two other Phytophthora genomes showed rapid turnover and extensive expansion of specific families of secreted disease effector proteins, including many genes that are induced during infection 
stage. These fast-evolving effector genes are localized to highly dynamic and expanded regions of the $P$. infestans genome. This probably plays a crucial part in the rapid adaptability of the pathogen to host plants and underpins its evolutionary potential (Haas et al., 2009). Other example of pathogen trainer of virulence factors is Botrytis cinerea to date have been identified a wide range of compounds and enzymes that uses the fungus to exerts its pathogenicity, thanks to the arsenal of degrading enzymes, $B$. cinerea is able to feed on different plant tissues, this fungus shares conserved virulence factors with other phytopathogens (Choquer et al., 2007). Botrytis cinerea is a ascomycete necrothrofic, this fungi alone is responsible for $10 \%$ of the global fungicide market (Fernandez-Acero et al., 2011), is thought to enter the host mainly by producing degrading enzymes and causing an oxidative burst, specifically because secretes nonspecific phytotoxins to kill cells from a large spectrum of plants. Among the numerous metabolites isolated from fermentation broths, the most well known is the sesquiterpene botrydial (Deighton et al., 2001). This fungus is notably equipped with multiple cell wall-degrading enzymes that allow plant tissue colonization and the release of carbohydrates for consumption. Pectin, the major host cell wall component, can be degraded by a set of fungal pectinases (Ten Have et al, 2001; Choquer et al, 2007). Xilanase (Xyn11A) from Botrytis cinerea contributes to the infection process with the necrotizing and not with the xylan hydrolyzing activity. The main contribution of the xylanase Xyn11A to the infection process of B. cinerea is to induce necrosis of the infected plant tissue. A conserved 30-amino acids region on the enzyme surface, away from the xylanase active site, is responsible for this effect and mediates binding to plant cells (Noda et al, 2010).

New technologies like proteomics are very good tools for obtain information about proteins secreted by pathogenic fungi. Nowadays, there is lot of candidate pathogenicity genes, but there is stagnation for their functional analysis, since experiments are time-consuming and difficult to realize for some fungi. However, genomic tools are already providing a much more integrated picture of pathogenicity mechanisms, compared with the previous focus on individual genes. Many fungal genes affecting disease progression are involved in growth and development, and there are few genes for which the only effect is on disease, proteomics allowed to identify between 10 and 100 different biological functions from each gene (Van De Wouw \& Howlett, 2011; Fernandez-Acero et al., 2011). This is an important progress in the new fungicide discovery because pathogenic genes with function in growth and development could be target site for new fungicides.

\section{Morphogenesis}

Since fungi are a eukaryotic organism, they have diverse metabolic profiles similar to many mammalian and plant. Hence, several antifungal agents discovered to be potentially active against plant pathogenic fungi have failed to survive during the testing process because the target site of the fungicide is found in another organism (Thines et al., 2004).

The most successful fungicide in the market today acts relatively broadly by targeting fungal vegetative growth and thus the entire fungal life cycle. Examples of a successful mode of action classes interfering with biochemical progresses essential in fungi include compounds targeting respiration and sterol biosynthesis. An example of the former mode of action class is given by compounds which target mitochondrial electron transport within the respiration chain. Fungicides of the strobilurin class have this mode of action. These 
compounds are structurally based on natural products and interfere with the ubiquinol cytochrome C oxidoreductase (Foster \& Thines, 2009).

There are numerous antifungal compounds that were discovered from diverse microbial sources using traditional activity-based screening techniques. These microbial compounds showed potent control efficacy against various plant diseases, including chronic diseases which are difficult to control with conventional synthetic fungicides. Advances in screening systems directed to specific targets of fungal metabolism have increased the opportunities to discover novel antifungal agents with selectivity over non-target organisms. Microbial metabolites have also been exploited as a source for non-fungicidal disease control agents that do not inhibit vegetative hyphal growth, but rather interfere specifically with the infection process of pathogenic fungi, such as spore germination, the formation of penetration structures and sporulation (Seok \& Kook, 2007). Infection structures of phytopathogenic fungi are modified hyphae specialized for the invasion of plant tissue, initial events are adhesion to the cuticule and directed growth of the germ tube on the plant surface (Mendgen et al., 1996). The specificity of microbial fungicides is a highly preferred characteristic in terms of impacting the environment, where it is closely related to the occurrence of fungicide resistance. The most recently developed fungicides from microbial metabolites, the strobilurins, provide a cue for the high risk of resistance development of site-specific fungicides.

These compounds have long been applied to control fungal diseases of rice, vegetables and fruits, and their effectiveness in controlling these diseases has been tested in the field and proven over many years. The importance of microbial fungicides, compared to synthetic compounds, may have been under evaluated in the past due to the limitation in their activity spectrum and in certain instances, the development of resistance (Knight et al., 1997). Nevertheless, the excellent fungicidal activity of these microbial metabolites and their potential as lead candidates for further fungicide development continue to stimulate research and screening for antifungal microbial metabolites, some examples of this compounds are:

Kasugamycin is an amino-sugar compound discovered from the metabolites of Streptomyces kasugaensis, in vivo studies have shown that kasugamycin efficiently suppresses the development of M. grisea mycelia on rice plants in both preventive and curative treatments, to overcome potential resistance problems, mixtures of kasugamycin with different synthetic fungicides having different modes of action are currently in use.

Polyoxins are peptidylpyrimidine nucleoside antibiotics isolated from the culture broth of Streptomyces cacaoi var. asoensis, such excellent characteristics come from the fact that polyoxins selectively inhibit the synthesis of cell-wall chitin in sensitive fungi but have no adverse effects on organisms lacking chitinous cell walls.

Validamycin A produced by Streptomyces hygroscopicus var. limoneus has been effective in controlling rice sheath blight caused by $R$. solani. Validamycin A is converted within fungal cells to validoxylamine A, an extremely strong inhibitor of trehalose. The mode of action of validamycin $\mathrm{A}$ is favorable for biological selectivity, because vertebrates do not depend on the hydrolysis of trehalose (Doumbou et al., 2001). 
Promising microbial metabolites continue to be discovered using traditional activity-based screening procedures against various plant pathogenic fungi. In particular, many of the sitespecific antifungal metabolites have recently been discovered from microbial metabolites. These microbial metabolites include non-fungicidal compounds that interfere with the infection process of pathogenic fungi, and specific inhibitors of the fungal biosynthetic pathways for chitin, fatty acids and nucleic acids (Seok \& Kook, 2007).

Other kind of antifungal agents are proteins; antifungal proteins have been isolated from various organisms ranging from bacteria, plants, insects and amphibians to human beings. Both their fungal target site and their mode of action are extremely diverse. In order for it to be applied, an antifungal protein needs to fulfill several prerequisites such as antifungal activity in vivo and lack of effects on the host cells. Furthermore, resistance mechanisms need to be excluded as far as possible. Therefore, investigation of the target site and the mode of action of an antifungal protein should reveal whether the protein is suitable for an application (Theis et al., 2005). The antifungal protein (AFP) are abundantly secreted by the filamentous fungus Aspergillus giganteus, this cysteine-rich protein have ability to disturb the integrity of fungal cell walls and plasma membranes but does not interfere with the viability of other eukaryotic systems (Barakat et al., 2010; Meyer, 2008).

Severe membrane alterations in $A$. niger were observed, whereas the membrane of $P$. chrysogenum was not affected after treatment with AFP. The protein localized predominantly to a cell wall attached outer layer which is probably composed of glycoproteins, as well as to the cell wall of $A$. niger. It was found to accumulate within defined areas of the cell wall, pointing towards a specific interaction of AFP with cell wall components. In contrast, very little protein was bound to the outer layer and cell wall of $P$. chrysogenum. The protein was found to act in a dose-dependent manner: it was fungistatic when applied at concentrations below the minimal inhibitory concentration, but fungicidal at higher concentrations. Using an in vivo model system was demonstrated that AFP indeed prevented the infection of tomato roots (Lycopersicon esculentum) by the plant-pathogenic fungus Fusarium oxysporum $\mathrm{f}$. sp. Lycopersici (Theis et al., 2005).

The fungal profilins, small actin-binding proteins that share limited homology to human profilin, can operate as a potential drug target, since these proteins are essential for the growth of most eukaryotic cells, including S. cerevisiae (Witke, 2004). Addition, the existence of structural information can support the design of structure-based ligands for profilins. Peptides are generally used as lead compounds in drug development, to design a novel peptide ligand, an in vitro evolution approach has often been used. Although this approach can be used without three-dimensional (3D) structural information about the target protein, it requires laborious experimental procedures, including library constructions and the screening of bioactive peptide ligands. In this respect, if information on the structure and the active site of the target protein is known, an in silico approach based on the 3D structure of the target protein is a useful approach to designing the peptide ligand. The validity of the profilin as antifungal drug target was evaluated by Ueno et al. 2010, amino acid alignments showed the low homology between human and fungal profilins. This implies that the fungal profilin could be a target with high selectivity. Furthermore, a mouse infection study showed that the suppression of profilin expression attenuated the fungal burden in the kidney and indicated that the profilin was required for survival in the host's body (Ueno et al., 2010). 
A major challenge for drug development today is how best to employ the new genome wide technologies to identify which metabolic pathways and gene products are critical for disease establishment and progression and thus to increase the probability of finding novel fungicide targets. Novel targets can be located either in biochemical or signaling pathways essential for vegetative growth or for pathogenic development of the fungus. Targets with high specificity can thereby be expected in pathways involved in adhesion, hostrecognition/pre-penetration processes, host colonization and the final reproductive differentiation processes during pathogenic development. An attractive proposition is the development of fungicides interfering with pathogenic development but not with vegetative growth. Such a strategy could prevent or cure infections by fungal pathogens without affecting neutral or benign species (Foster \& Thines, 2009).

\section{Conclusion}

We would like to conclude by stating that antifungal targets-site are extremely diverse. However, substances that acts on these target-sites needs to fulfill several prerequisites such as antifungal activity in vivo and lack of effects on the host cells. Furthermore, resistance mechanisms need to be excluded as far as possible. Therefore, investigation of the target site and the mode of action of an antifungal compound can be explored by statistical learning algorithms. Performance and applicability of the statistical learning methods in studying "fungal-target likeness" may be further improved by incorporation of new information from advances in genomic, proteomics, pathogenesis and morphogenesis studies. Efficiency and accuracy of statistical learning methods in the prediction of fungal-target like proteins can also be enhanced from new progress in learning algorithms and sequence descriptors.

\section{References}

Abramovitch, R. B., Anderson, J. C. \& Martin, G. B. (2006). Bacterial elicitation and evasion of plant innate immunity. Nature Reviews Molecular Cell Biology. 7:601-611.

Albeck, S., Alzari, P., Andreini, C. , Banci, L., Berry, M., Bertini, I.,Cambillau, C., Canard, B., Carter, L., Cohen, S. X., Diprose, J. M., Dym, O., Esnouf, R. M., Felder, C., Ferron, F., Guillemot, F., Hamer, R., Ben Jelloul, M., Laskowski, R. A., Laurent, T., Longhi, S. Lopez, R., Luchinat, C., Malet, H., Mochel, T., Morris, R. J., Moulinier, L., Oinn, T.,Pajon, A., Peleg, Y., Perrakis, A., Poch, O., Prilusky, J., Rachedi, A., Ripp, R., Rosato, A., Silman, I., Stuart, D. I., Sussman, J. L., Thierry, J.C., Thompson, J. D.,Thornton, J. M., Unger, T.,Vaughan, B., Vranken, W., Watson, J. D., Whamondg, G. \& Henrickg K. (2006). SPINE bioinformatics and data management aspects of high throughput structural biology. Acta Chrystallographic. D62:11841195.

Barakat, H. Spielvogel, A., Hassan, M., El-Desouky A., El-Mansy H., Rath, F. Meyer, V. \& Stahl, U. (2010). The antifungal protein AFP from Aspergillus giganteus prevents secondary growth of different Fusarium species on barley. Applied Microbiology and Biotechnology. 87:617-624. 
Brent, K.J. and Hollomon, D.W. Fungicide Resistance in Crop Pathogens: How Can it be Managed?. Manuscript, Fungicide Resistance Action Committee, CROPLIFE INTERNATIONAL, Brussels, Belgium (2007). Available from http://www. frac.info/frac/publication/publication.htm. Reviewed on June 24, 2011.

Choquer, M., Fournier, E., Kunz, C., Levis, C., Pradier, J., Simon, A. \& Viaud, M. (2007). Botrytis cinerea virulence factors: new insights into a necrotrophic and polyphageous pathogen. Minireview. Journal compilation. Federation of European Microbiological Societies, Microbiological letters. 277:1-10.

Deighton, N., Muckenschnabel, I., Colmenares, A.J., Collado, I.G. \& Williamson, B. (2001). Botrydial is produced in plant tissues infected by Botrytis cinerea. Phytochemistry 57: 689-692.

Doumbou, C.L., Hamby, S. M., Crawford, D. L. \& Beaulieu, C. (2001). Actinomycetes, promising tools to control plant diseases and to promote plant growth. Phytoprotection. 82: 85-102.

Fernandez-Acero, F., Carbú, M., El-Akhal, M., Garrido, C., Gonzalez-Rodriguez, V. \& Cantoral, J. (2011). Development of proteomics based fungicides: New strategies for environmentally friendly control of fungal plant disease. International Journal of Molecular Science. 12:795-816.

Fernández-Acero, F.J., Colby, T., Harzen, A., Carbú, M., Wieneke, U., Cantoral, J.M. \& Schmidt, J. (2010). 2-DE proteomic approach to the Botrytis cinerea secretome induced with different carbon sources and plant-based elicitors. Proteomics. 10:2270-2280.

Fernandez-Acero, F.J., Carbú, M., Garrido, C., Collado, I. G., Cantoral, J. \& Vallejo, I. (2006). Screening study of potential lead compounds for natural products based fungicides against Phytophthora species. Journal of phytopathology. 154, 616-621.

Foster, A. \& Thines, E. (2009). Identification of fungicide targets in pathogenic fungi. The Mycota. A comprehensive treatise on fungi as experimental system for basic and applied research. Physiology and Genetics XV. Springer. Germany. Pp.232.

Ferrer-Alcon, M., Arteta, D., Guerrero, M.J., Fernandez-Orth, D., Simon, L. \& Martinez, A. (2009). The use of gene array technology and proteomics in the search of new targets of diseases for therapeutics. Toxicology letters. 186: 45-51.

Garrido, C., Cantoral, J.M., Carbu, M., Gonzalez-Rodriguez, \& V. Fernandez-Acero, F. (2010). New proteomic approaches to plant pathogenic fungi. Current Proteomics. 7:306-315

Gonzalez-Fernandez, R., Prats, E. \& Jorrın-Novo, J. V. (2010). Proteomics of Plant Pathogenic Fungi. Journal of Biomedicine and Biotechnology. 2010;ID 932527, 36 p.

Gustafson, D. I. (2011). Climate change: a crop protection challenge for the twenty-first century. Pest Management Science. 67:691-696.

Haas, B. J., Kamoun, S., Zody, M., Jiang, R., Handsaker R., Cano, L., Grabherr M., Kodira, C., Raffaele, S. \& Torto-Alalibo, T. (2009). Genome sequence and analysis of the Irish potato famine pathogen Phytophthora infestans. Nature. 461:393-398. 
Hogenhout, S., Van der Hoorn, R., Terauchi, R. \& Kamoun S. (2009). Emerging concepts in effector biology of plant-associated organisms. Molecular Plant-Microbe Interaction. 22: $115-122$.

Idnurm, A. \& Howlett, B. (2001). Phatogenicity genes of phytopathogenic fungi. Molecular Plant Pathology. 2:241-255.

Knight, S.C., Anthony, V.M., Brady A. M., Greenland, A.J., Heaney, S.P., Murray, D.C., Powell, K. A., Schulz, C.A., Spinks, C. A., Worthington, P. A. \& Youle, D. (1997). Rationale and perspectives on the development of fungicides. Annual Review of Phytopathology. 35:349-372.

Marrero-Ponce, Y., Meneses-Marcel, A., Rivera-Borroto, O.M., Garcia-Domenech, R., De Julian-Ortiz, J.V., Montero, A. (2008). Bond-based linear indices in QSAR: computational discovery of novel anti-trichomonal compounds. Journal of Computer Aided Molecular Desing. 22:523-540.

Mendgen, K., Hahn, M. \& Deising, H. (1996). Morphogenesis and Mechanisms of penetration by plant pathogenic fungi. Annual Review of Phytopathology. 34:367-386.

Meyer, V. (2008). A small protein that fights fungi: AFP as a new promising antifungal agent of biotechnological value. Applied Microbiology and Biotechnology. 78:17-28.

Noda, J., Brito, N. \& Gonzalez, M. (2010). The Botrytis cinerea xylanase Xyn11A contributes to virulence with its necrotizing activity, not with its catalytic activity. BMC Plant Biology. 10:38-47.

Oliver, R.P. \& Solomon, P.S. (2010). New developments in pathogenicity and virulence of necrotrophs. Current Opinion in Plant Biology. 13, 1-5.

Russell, D. (2003). Similarities and differences in the responses of microorganisms to biocides. Journal of Antimicrobial Chemotherapy. 52: 750-763

Santos, M., Diánez, F., de Cara, M. \& Tello, J.C.(2008). Possibilities of the use of vinasses in the control of fungi phytopathogens. Bioresource Technology. 99: 9040-9043.

Seok, B. \& Kook, B. (2007). Microbial Fungicides in the Control of Plant Diseases. Journal of Phytopathology. 155, 641-653

Singh, S. \& Sharma, D. (2011). In silico modeling in conjunction with natural products: Paving the way for drug design. Biotechnology and Molecular Biology Review. 6:88-93.

Speck-Planche, A., Guilarte-Montero.L., Yera-Bueno. R., Rojas-Vargas, J., Garcia-López, L.A., Uriarte, E. \& Molina-Pérez, E. (2011). Rational design of new agrochemicals fungicides using substructural descriptors. Pest Management Science. 67:438-445.

Steffens, J. J., Pellt, J.E. \& Tien, M. (1996). Mechanisms of fungicide resistence in phytopathogenic fungi. Current Opinion in Biotechnology. 7:348-355

Ten Have, A., Breuil, W.O., Wubben, J.P., Visser, J. \& Van Kan, J.A. (2001). Botrytis cinerea endopolygalacturonase genes are differentially expressed in various plant tissues. Fungal Genetics and Biology. 33: 97-105.

Theis, T., Marx, F., Salvenmoser W., Stahl U., \& Meyer, V. (2005). New insights into the target site and mode of action of the antifungal protein of Aspergillus giganteus. Research in Microbiology. 156: 47-56.

Thines, E., Anke, H. \& Weber, W.S. (2004). Fungal secondary metabolites as inhibitors of infection-related morphogenesis in phytopathogenic fungi. Mycological Research. 108:14-25. 
Ueno, K. Tamura, Y. \& Chibana, H. (2010). Target validation and ligand development for a pathogenic fungal profilin, using a knock-down strain of pathogenic yeast Candida glabrata and structure-based ligand design. Yeast. 27: 369-378.

Van De Wouw, A. \& Howlett, B. (2011). Fungal pathogenicity genes in the age of 'omics'. Molecular Plant Pathology. 12: 507-514.

Witke, W. (2004). The role of profilin complexes in cell motility and other cellular processes. Trends Cell Biology. 14: 461-469.

Xu, H., Xu, H., Lin, M., Wang, W., Li, Z., Huang, J., Chen, Y., Chen, X. (2007). Learning the drug target-likeness of a protein. Proteomics. 7: 4255-4263. 


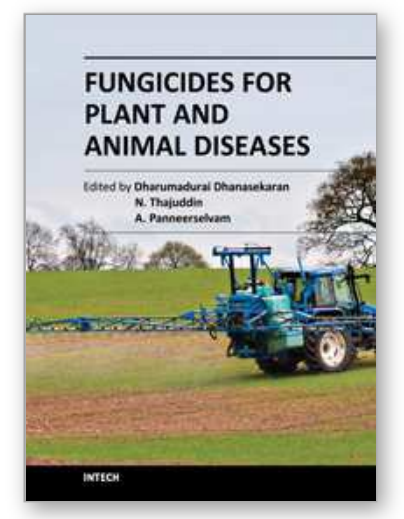

\author{
Fungicides for Plant and Animal Diseases \\ Edited by Dr. Dharumadurai Dhanasekaran
}

ISBN 978-953-307-804-5

Hard cover, 298 pages

Publisher InTech

Published online 13, January, 2012

Published in print edition January, 2012

A fungicide is a chemical pesticide compound that kills or inhibits the growth of fungi. In agriculture, fungicide is used to control fungi that threaten to destroy or compromise crops. Fungicides for Plant and Animal Diseases is a book that has been written to present the most significant advances in disciplines related to fungicides. This book comprises of 14 chapters considering the application of fungicides in the control and management of fungal diseases, which will be very helpful to the undergraduate and postgraduate students, researchers, teachers of microbiology, biotechnology, agriculture and horticulture.

\title{
How to reference
}

In order to correctly reference this scholarly work, feel free to copy and paste the following:

Consuelo Corrales-Maldonado, Miguel Angel Martinez-Téllez and Irasema Vargas-Arispuro (2012). TargetSite-Specific Screening System for Antifungal Compounds, Fungicides for Plant and Animal Diseases, Dr. Dharumadurai Dhanasekaran (Ed.), ISBN: 978-953-307-804-5, InTech, Available from:

http://www.intechopen.com/books/fungicides-for-plant-and-animal-diseases/target-site-specific-screeningsystem-for-antifungal-compounds

\section{INTECH}

open science | open minds

\section{InTech Europe}

University Campus STeP Ri

Slavka Krautzeka 83/A

51000 Rijeka, Croatia

Phone: +385 (51) 770447

Fax: +385 (51) 686166

www.intechopen.com

\section{InTech China}

Unit 405, Office Block, Hotel Equatorial Shanghai

No.65, Yan An Road (West), Shanghai, 200040, China

中国上海市延安西路65号上海国际贵都大饭店办公楼405单元

Phone: +86-21-62489820

Fax: $+86-21-62489821$ 
(C) 2012 The Author(s). Licensee IntechOpen. This is an open access article distributed under the terms of the Creative Commons Attribution 3.0 License, which permits unrestricted use, distribution, and reproduction in any medium, provided the original work is properly cited. 